\title{
A instrumentalidade no cotidiano de trabalho do/a assistente social no âmbito da proteção social especial
}

\author{
The instrumentality in the social worker's daily word in the context of special social protection \\ La instrumentalidad en el trabajo diario del trabajador social en el contexto de la protección social \\ especial
}

Recebido: 08/10/2021 | Revisado: 13/10/2021 | Aceito: 18/10/2021 | Publicado: 21/10/2021

Tatiane Aurélio de Sousa

ORCID: https://orcid.org/0000-0002-1138-9512 Faculdade do Maciço de Baturité, Brasil E-mail: tatianeaurelioas@gmail.com

\begin{abstract}
Resumo
O presente artigo objetiva discorrer sobre a importância da instrumentalidade no cotidiano de trabalho do/a assistente social. Para tanto, tornou-se necessário contextualizar a dimensão teórica abordada por autores que dialogam sobre o tema, como, por exemplo, Yolanda Guerra, tecendo fios com o espaço de trabalho da pesquisadora como eixo central de discussão, apresentando a visita domiciliar como instrumento metodológico de trabalho em destaque nos serviços executados no Centro de Referência Especializada de Assistência Social (CREAS) de Novo Oriente/CE. Não obstante, a discussão se dá levando em consideração o atual contexto de pandemia da Covid-19 em que o país se encontra, refletindo diretamente no cotidiano familiar, social e de trabalho. A metodologia utilizada consiste no formato bibliográfico e pesquisa de campo, com a pretensão de refletir e explanar acerca dos diferentes tipos de instrumentos e técnicas que podem ser utilizadas para materialização dos atendimentos e as demandas apresentadas ao equipamento, em específico a visita domiciliar, objeto de estudo desta pesquisa, tomando por base o aporte teórico sobre do tema, os quais, na prática profissional, transformam-se em meios para a objetivação das intencionalidades junto aos sujeitos de sua ação.
\end{abstract}

Palavras-chave: Instrumentalidade; Prática profissional; Proteção social especial.

\begin{abstract}
This experience report aims to discuss the importance of instrumentality in the daily work of the Social Worker. Therefore, it became necessary to contextualize the theoretical dimension addressed by authors who dialogue on the topic, such as Yolanda Guerra, weaving threads with the researcher's work space as the central axis of discussion, presenting the home visit as a methodological instrument of highlighted work in the services performed at the Specialized Reference Center for Social Assistance - CREAS in Novo Oriente/CE. Nevertheless, the discussion takes into account the current context of the Covid-19 pandemic that the country is in, directly reflecting on the family, social and work routine. The methodology used consists of the bibliographic format and field research, with the intention of reflecting and explaining the different types of instruments and techniques that can be used to materialize the demands presented to the equipment, in particular, the home visit, object of study of this report, based on the theoretical contribution about the theme, which in professional practice become means for the objectification of intentions together with the subjects of their action.
\end{abstract}

Keywords: Instrumentality; Professional practice; Special social protection.

\section{Resumen}

Este artículo tiene como objetivo discutir la importancia de la instrumentalidad en el trabajo diario del trabajador social. Por tanto, se hizo necesario contextualizar la dimensión teórica abordada por autores que dialogan sobre el tema, como Yolanda Guerra, tejiendo hilos con el espacio de trabajo de la investigadora como eje central de discusión, presentando la visita domiciliaria como un instrumento metodológico destacado en los servicios. realizado en el Centro de Referencia Especializado de Asistencia Social (CREAS) en Novo Oriente / CE. Sin embargo, la discusión toma en cuenta el contexto actual de la pandemia Covid-19 en el que se encuentra el país, reflejando directamente la rutina familiar, social y laboral. La metodología utilizada consiste en el formato bibliográfico y la investigación de campo, con la intención de reflexionar y explicar sobre los diferentes tipos de instrumentos y técnicas que se pueden utilizar para materializar los servicios y las demandas que se presentan a los equipos, específicamente la visita domiciliaria, el objeto de estudio de esta investigación, a partir del aporte teórico sobre el tema, que, en la práctica profesional, se transforma en medios para la objetivación de intenciones con los sujetos de su acción.

Palabras clave: Instrumentalidad; Ejercicio profesional; Protección social especial. 


\section{Introdução}

É notório dizer que no Serviço Social é necessário permanecer buscando novas fontes de conhecimento para possibilitar intervenções profissionais que dialoguem com o cenário social atual, uma vez que, a cada modelo de sociedade presente, reconfigura-se as relações de trabalho, exigindo mais competências e habilidades profissionais, e um dos caminhos para fomentar tal questão se dá por meio da pesquisa.

Ora, não se pode deixar de mencionar o quão é desafiador o descortinar de uma pesquisa em seus diversos aspectos, que consistem em tempo, dedicação e disponibilidade para leituras. Desafio no que se refere à visão introspectiva, de refletir além da realidade apresentada, ir além do que se aprendeu, além do que está posto no momento. Desafio porque remete a pensar a grande problemática que envolve teoria e prática no Serviço Social e, nesse contexto, sua instrumentalidade, objetivo de pesquisa deste estudo.

Nesse sentido, as impressões contidas nesse trabalho têm como objetivo refletir sobre a importância da instrumentalidade no cotidiano profissional do/a assistente social no âmbito da proteção social especial, evidenciada sob o viés da análise das atividades ofertadas à população usuária, como, por exemplo, a visita domiciliar através do Centro de Referência Especializado de Assistência Social (CREAS) de Novo Oriente/CE, espaço de trabalho da assistente social responsável pela construção do estudo.

No entanto, é de suma importância destacar o impacto que a pandemia da Covid-19 incide no Brasil desde meados de março de 2020, ocasionando mais de 500 mil mortes até outubro de 2021, ocasionando o fechamento geral do comércio, acréscimo do desemprego e violência em suas mais variadas nuances, limitação na oferta dos serviços e condições de acesso dos/as usuários/as aos serviços. Esse contexto apresentou curva positiva com a chegada da vacina desde o início de 2021, resultando na flexibilização das atividades econômicas, políticas e sociais no país.

Em consonância com o atual contexto pandêmico, o município de Novo Oriente vem atuando, desde o início da pandemia, em conformidade com os decretos estaduais do Ceará ${ }^{1}$, adequando-se às necessidades locais levando em consideração os dados diários do boletim epidemiológico veiculado nos diferentes canais de comunicação. Diante desse aspecto, o CREAS estabeleceu o planejamento das atividades considerando os dados do boletim para conduzir a execução dos serviços.

Não obstante, é imprescindível tecer fios sobre o Sistema Único de Assistência Social (SUAS) para promover a compreensão do tema em discussão. Apresenta-se o marco temporal da década de 1980 como reflexo de grandes transformações no Brasil, principalmente no que concerne ao reordenamento do Estado referente às políticas sociais, decorrente de inúmeras lutas e movimentos sociais. Em resposta às manifestações da sociedade civil, foram implantadas as medidas de política econômica e social.

Além disso, em 1988 houve a reformulação da Constituição Federal, que apresentou mudanças significativas a respeito da proteção social no Brasil, representada através do Artigo 194 (Brasil, 2001), que diz: "A seguridade social compreende um conjunto integrado de ações de iniciativa dos Poderes Públicos e da sociedade destinadas a assegurar os direitos relativos à saúde, à previdência e à assistência social”.

Portanto, a partir das leituras e do arcabouço teórico sobre a importância da instrumentalidade no cotidiano de trabalho, iniciaram-se as primeiras inquietações para aprofundar a reflexão acerca da finalidade com relação à utilização dos instrumentos como a visita domiciliar, a entrevista, o acompanhamento social e acolhimento social, identificados como instrumentos mais recorrentes no CREAS de Novo Oriente/CE, espaço de trabalho da pesquisadora.

\footnotetext{
${ }^{1}$ Desde o início da pandemia da Covid-19, em março de 2020, o governo do estado do Ceará tem lançado decretos que regulamentam o funcionamento do comércio e demais atividades coletivas, dentre as quais se destacam os setores da saúde e educação. O primeiro foi o Decreto n. 33.510, de 16 de março de 2020 (Ceará, 2020), o mais recente foi o Decreto n. 34.254, de 18 de setembro de 2021 (Ceará, 2021 ).
} 
A metodologia utilizada para a estruturação do relato de experiência se dá através da pesquisa bibliográfica e observação de campo, pois, segundo Marconi e Lakatos (1992), essa metodologia consiste no levantamento de toda a bibliografia já publicada, em forma de livros, revistas, publicações avulsas e imprensa escrita, além de ser considerada como primeiro passo de todo o processo para construção da escrita.

Já a pesquisa de campo, segundo Gonçalves (2001, p. 67), “[...] é o tipo de pesquisa que pretende buscar a informação diretamente com a população pesquisada". Nesse caso, o pesquisador precisa ir ao espaço onde o fenômeno ocorre, ou ocorreu, e reunir um conjunto de informações a serem documentadas. Ou seja, o uso de diferentes métodos e metodologias se faz necessário para embasar a construção do estudo, uma vez que se trata da realidade profissional vivenciada pela pesquisadora no CREAS, que é também seu campo de atuação e espaço de pesquisa.

O artigo apresenta sua fundamentação teórica sob a óptica de autores como Yolanda Guerra (2007) e Marilda Vilela Iamamoto (2004), que apresentam em seus arcabouços teóricos os pressupostos que fomentam a prática profissional alinhada à reflexão do cotidiano frente aos instrumentos e técnicas usados para resolução das demandas apresentadas à assistente social do CREAS.

Espera-se que as contribuições apresentadas neste estudo venham a contribuir com pesquisas futuras, como também intervir na realidade profissional dos/as assistentes sociais que atuam na proteção social especial por meio das impressões vivenciadas e elencadas através desta pesquisa.

\section{A política de Assistência Social e Serviço Social: tecendo fios com o relato de experiência}

Conforme citado na apresentação deste trabalho, o marco temporal para contextualizar as transformações ocorridas no âmbito do Estado é marcado pela década de 1980, as quais são oriundas das lutas e movimentos populares em resposta à sociedade e legitimadas através do Art. 194 da Constituição Federal (Brasil, 2001), que instituiu a seguridade social, articulada pelas políticas de saúde, sendo universal, assistência social, para quem dela necessita, e previdência social, de cunho contributivo, dando início à política de assistência social no Brasil.

A importância de conceituar teoricamente o que a política apresenta enquanto normativo de operacionalização se dá pela necessidade de compreender a dinâmica histórica em que a política se concretiza no que corresponde ao caráter técnico da profissão, uma vez que o direcionamento se dá de forma descentralizada. Dessa forma, faz-se necessário que o/a profissional tenha conhecimento do arcabouço teórico, pois, conforme Freire (2003, n.p): "É fundamental diminuir a distância entre o que se diz e o que se faz, de tal forma que, num dado momento, a tua fala seja a tua prática".

A Constituição Federal de 1988 define que a seguridade social compreende um conjunto integrado de ações de iniciativa dos poderes públicos e da sociedade destinados a assegurar os direitos relativos à Saúde, à Previdência Social e à Assistência Social (Brasil, Art. 194, 2001).

Sua organização se dá através dos princípios e objetivos, que são: universalidade de cobertura; atendimento; equidade, uniformidade e equivalência urbanas e rurais; seletividade e distributividade; irredutibilidade dos valores de benefícios; diversidade da base de financiamento; gestão democrática descentralizada e participativa.

De acordo com Carneiro, seguridade significa:

Um sistema protetivo estatal voltado ao atendimento das necessidades básicas do ser humano, e cuja ideia central é justamente a de propiciar aos indivíduos e suas famílias tranquilidade para que, na ocorrência de uma determinada contingência (e.g., invalidez, morte etc.), a qualidade de vida não seja significativamente diminuída (Carneiro, 2010, p. $1)$.

A partir do exposto, compreende-se que a assistência é um dos eixos fundantes do tripé da seguridade social, e também a política que é destinada a quem dela necessita, atuando por meio dos diversos serviços ofertados, oferecendo apoio e 
acolhimento necessário diante das fragilidades das famílias e indivíduos. Tem como valor central a dignidade da pessoa humana, atuando na viabilização de direitos à garantia da sobrevivência em condições dignas e consolidando o que apresenta a Constituição Federal de 1988:

Art. 203. A assistência social será prestada a quem dela necessitar, independentemente de contribuição à seguridade social, e tem por objetivos: I - a proteção à família, à maternidade, à infância, à adolescência e à velhice; II - o amparo às crianças e adolescentes carentes; III - a promoção da integração ao mercado de trabalho; IV - a habilitação e reabilitação das pessoas portadoras de deficiência e a promoção de sua integração à vida comunitária; V - a garantia de um salário mínimo de benefício mensal à pessoa portadora de deficiência e ao idoso que comprovem não possuir meios de prover à própria manutenção ou de tê-la provida por sua família, conforme dispuser a lei (Brasil, 2001).

Em consonância com os avanços no cenário do Estado, foi promulgada em 1993 a Lei Orgânica de Assistência Social (LOAS) através da Lei n. ${ }^{\circ}$ 8.742/93 (BRASIL, 1993), regulamentando a Constituição Federal, estabelecendo normas e critérios para a operacionalização da política de assistência social. A referida lei define em seu Art. $2^{\circ}$ que:

A assistência social, direito do cidadão e dever do Estado, são uma política de seguridade social não contributiva, que provê os mínimos sociais, realizada através de um conjunto integrado de iniciativa pública e da sociedade civil, para garantir o atendimento às necessidades básicas (Brasil, 1993, Art. $2^{\circ}$ ).

Além disso, é importante pontuar o papel que a Norma Operacional Básica (NOB) da SUAS, que é componente elementar para a implantação do SUAS através do Conselho Nacional de Assistência Social (CNAS) em 2005, momento responsável por organizar a operacionalização da política de assistência e transição para o modelo atual.

Em virtude da criação das políticas e da legitimação do SUAS, Couto et al. ressaltam que:

A PNAS/2004 vai tornar claras as diretrizes para que a assistência social possa se efetivar enquanto um direito do cidadão e de dever do Estado, apoiada em um modelo de gestão compartilhada através do pacto federativo na qual são detalhadas as atribuições e competências de cada esfera do governo na provisão das ações e atenções socioassistenciais (C et al., 2010, n.p).

Os serviços da Proteção Social Básica são executados de forma direta nos Centros de Referência de Assistência Social $(\mathrm{CRAS})^{2}$ e, através de outras unidades básicas e públicas de assistência social e/ou entidades e organizações de assistência social, em especial os Serviços de Convivência e Fortalecimento de Vínculos, bem como o Serviço de Proteção Social Básica no Domicílio para Pessoas com Deficiência e Idosas, devem ser a ele referenciados e manter articulação com o Serviço de Proteção e Atendimento Integral à Família (PAIF)

Os serviços ofertados na proteção social especial são classificados de acordo com o grau de complexidade e subdividido em dois níveis, sendo serviços de proteção social de média complexidade e alta complexidade.

O CREAS se constitui numa unidade pública e estatal em que se ofertam serviços especializados e continuados a famílias e indivíduos nas diversas situações de violação de direitos. Como unidade de referência, deve promover a integração de esforços, recursos e meios para enfrentar a dispersão dos serviços e potencializar ações para os/as usuários/as.

No que corresponde ao atendimento do CREAS de Novo Oriente no contexto pandêmico, atualmente oferta seus serviços seguindo o plano de contingência no período de $07 \mathrm{~h}$ às $12 \mathrm{~h}$, tendo como carro-chefe o Serviço de Proteção e Atendimento Especializado as Famílias e Indivíduos (PAEFI). A realização de visitas domiciliares se dá em caráter de urgência,

\footnotetext{
${ }^{2}$ Centro de Referência de Assistência Social, unidade pública estatal descentralizada da Política Nacional de Assistência Social (PNAS). Atua como a principal porta de entrada do SUAS, dada sua capilaridade nos territórios, e é responsável pela organização e oferta de serviços da Proteção Básica nas áreas de vulnerabilidade social.

${ }^{3}$ O PAIF é um trabalho de caráter continuado que visa a fortalecer a função de proteção das famílias, prevenindo a ruptura de laços, promovendo o acesso e usufruto de direitos e contribuindo para a melhoria da qualidade de vida. Recuperado de www.mds.gov.br
} 
agendamento para atendimento institucional, além do acompanhamento e atendimento de demanda espontânea ou anônima no formato remoto enquanto perdurar o cenário atual.

Os serviços ofertados no CREAS são: Serviço de Proteção e Atendimento Especializado a Famílias e Indivíduos $(\mathrm{PAEFI})^{4}$; Serviço Especializado em Abordagem Social; Serviço de Proteção Social a Adolescentes em Cumprimento de Medida Socioeducativa de Liberdade Assistida (LA) e de Prestação de Serviços à Comunidade (PSC); Serviço de Proteção Social Especial a Pessoas com Deficiência, Idosos/as e suas Famílias; Serviço Especializado para Pessoas em Situação de Rua.

Dentre os serviços da Proteção Social Especial mencionados acima, no atual contexto pandêmico o CREAS de Novo Oriente atua com a oferta do PAEFI e cumprimento de medida socioeducativa em meio aberto através da prestação de serviço à comunidade e construção de projetos destinados para pessoas em situação de rua e violência doméstica, intitulado "De mãos dadas por Marias", extensão do "Projeto Marias", que tem Juazeiro como cidade pioneira, ainda em fase de implementação. Além disso, oferta atendimento institucional através de demanda espontânea ou anônima e acolhimento social. Nessa perspectiva, apresenta-se como foco de análise a visita domiciliar enquanto instrumento de trabalho.

De acordo com a Tipificação Nacional de Serviços Socioassistenciais, a PSE de Alta Complexidade inclui os seguintes serviços: Serviço de Acolhimento Institucional, nas seguintes modalidades: Abrigo institucional, Casa-Lar, Casa de Passagem, Residência Inclusiva; Serviço de Acolhimento em República; Serviço de Acolhimento em Família Acolhedora; Serviço de Proteção em Situações de Calamidades Públicas e de Emergências.

Portanto, a oferta dos serviços objetiva a preservação, fortalecimento e resgate dos vínculos familiares e comunitários, como também o empoderamento das famílias e indivíduos no que corresponde aos seus direitos diante da demanda.

\section{A instrumentalidade no trabalho do/a Assistente Social}

A discussão apresentada neste tópico consiste na análise da dimensão da instrumentalidade sob a óptica da autora Yolanda Guerra (2007), que apresenta em seu arcabouço teórico a importância desse eixo norteador no cotidiano de trabalho do/a assistente social.

Desse modo, faz-se necessário compreender a instrumentalidade “[...] como uma propriedade ou um determinado modo de ser que a profissão adquire no interior das relações sociais, no confronto entre as condições objetivas e subjetivas do ex ercício profissional" (Guerra, 2007, p. 1), ou seja, deve-se vê-la como uma propriedade constitutiva da profissão construída e reconstruída de forma sócio-histórica, para que, assim, constitua-se em condição de reconhecimento social da profissão.

De acordo com Guerra:

A instrumentalidade é uma propriedade e/ou capacidade que a profissãovai adquirindo na medida em que concretiza objetivos. Ela possibilita que os profissionais objetivem sua intencionalidade em respostas profissionais. É por meio desta capacidade, adquirida no exercício profissional, que os assistentes sociais modificam, transformam, alteram as condições objetivase subjetivas e as relações interpessoais e sociais existentes num determinado nível da realidade social: no nível do cotidiano (Guerra, 2007, p. 02).

No entanto, além de conhecer dada realidade social e saber quais instrumentos e técnicas utilizar para realizar intervenção, faz-se necessário ter clareza a respeito dos três requisitos pertinentes à competência profissional, sendo a dimensão ético-política, teórico-metodológica e técnico-operativa.

No que corresponde ao percurso histórico do serviço social no Brasil, a construção da instrumentalidade teve seu início ainda na década de 1930, com a criação da profissão, tendo esta, na década de 1980, uma redefinição de seu direcionamento social face do movimento de renovação do serviço social. Sendo que a década de 1980 é vista na profissão como uma fase de

\footnotetext{
${ }^{4}$ O Serviço de Proteção e Atendimento Especializado a Famílias e Indivíduos (PAEFI) oferta apoio, orientação e acompanhamento especializado a famílias e indivíduos em situação de ameaça ou violação de direitos.
} 
"maioridade intelectual" (Netto, 2005, p. 275), pois teve muitas produções de avanços críticos. Esse contexto contribuiu para uma visão crítica da sociedade e da profissão, principalmente no que compete ao rompimento com os paradigmas da caridade e benevolência, passando a exigir da categoria profissional perfil técnico, como também a inserção do serviço social na divisão social técnica do trabalho na sociedade capitalista.

Iamamoto (2004) apresenta as reflexões acerca da gestação da questão social enquanto matéria prima do serviço social, mais especificamente, caracterizando o período de ascenção do capitalismo monopolista que apresenta as inúmeras expressões da questão social, neste sentido, a autora afirma que:

O Serviço Social tem na "questão social" a base de sua fundação enquanto especialização do trabalho. "Questão social" apreendida enquanto o conjunto das expressões das desigualdades da sociedade capitalista que tem uma raiz comum: a produção social é cada vez mais social, enquanto a apropriação dos seus frutos mantém-se privada, monopolizada por uma parte da sociedade (Iamamoto, 2004, p. 16).

O Serviço Social se constitui no âmbito das relações sociais, na qual, é o seu palco de atuação, que estão em contínua dinâmica e sofrendo modificações juntamente com a sociedade (Bravaresco; Goin, 2009). Em consonância com as mudanças que ocorrem na sociedade, a instrumentalidade precisa ser compreendida na perspectiva que se estabelece a dinâmica social, do modo de produção capitalista, como também, atentando-se para a inserção de novas tecnologias.

A instrumentalidade no exercício profissional do/a assistente social parece ser algo referente ao uso daqueles instrumentos necessários ao agir profissional, através dos quais os assistentes sociais podem efetivamente objetivar suas finalidades em resultados profissionais (Guerra, 2008, p. 01).

A instrumentalidade nesse sentido, é compreendida para além do conjunto de instrumentos e técnicas que circunda o processo de trabalho do/a assistente social em seus múltiplos espaços profissionais. Pontuando assim, que a instrumentalidade é um conjunto de conhecimentos que se desvela através do trabalho do/a assistentente social, levando em consideração as dimensões teórico metodológico, ético político e técnico operativo da profissão.

Não obstante, os instrumentos de trabalho do/a assistente social são os maiores mediadores no que concerne ao desenvolvimento da prática profissional, pois são partes indissociáveis do trabalho e artifícios necessários para compreender a realidade social. A necessidade de compreender o conjunto de instrumentos que regem o cotidiano se dá também pela importância de conhecer o contexto em que se estabelecem tais relações e verificar de que forma podem ser aplicadas, na busca de construir mediações da prática profissional baseadas em finalidade interventiva no que tange às respostas às demandas apresentadas.

É oportuno salientar que as intervenções profissionais são antecedidas do conhecimento da demanda e do planejamento que é realizado para identificar qual método e instrumento usar para atender à realidade. É indispensável que o/a assistente social utilize diferentes instrumentos e técnicas para exercer sua ação. Vale ressaltar que cada demanda traz consigo particularidades próprias, portanto, compete ao profissional optar pelos instrumentos que melhor atendem às necessidades dos usuários, tomando por base a finalidade da intervenção objetivando atingir resultados satisfatórios para além do momento atual.

Nesse sentindo, visualiza-se a possibilidade de intervir nas expressões da questão social por diversos caminhos. Nos termos de Iamamoto:

Requisita um perfil profissional culto, crítico e capaz de formular, recriar e avaliar propostas que apontem para a progressiva democratização das relações sociais. Exige-se, para tanto, compromisso ético-político com os valores democráticos e competência teórico-metodológica na teoria crítica em sua lógica de explicação da vida social. Esses elementos, aliados à pesquisa da realidade, possibilitam decifrar situações particulares com que se defronta o assistente social no seu trabalho, de modo a conectá-las aos processos sociais macroscópicos que as geram e as modificam. Mas, requisita, também, um profissional versado no instrumental técnico- operativo capaz de potencializar as ações nos níveis de assessoria, planejamento, negociação, pesquisa e ação direta, estimuladora da participação dos sujeitos 
sociais nas decisões que lhes dizem respeito, na defesa de seus direitos e no acesso aos meios de exercê-los (Iamamoto, 2004, p. 208).

Diante do leque de instrumentos a serem utilizados no cotidiano de trabalho do/a assistente social, o foco se dá na ação da visita domiciliar enquanto elemento de apreensão da realidade. Acerca do uso da visita domiciliar como metodologia de trabalho, faz-se necessário rememorar a finalidade dessa ação como algo fiscalizador, ditador de regras e comportamento das famílias em sociedade através da regulação do Estado. Atualmente, a atividade faz parte dos instrumentos e técnicas de trabalho do/a assistente social, fundamentado pelo projeto ético político da profissão, embora apresente ranço conservador em sua materialização.

A visita domiciliar é um dos instrumentos que potencializa as condições de conhecimento do cotidiano dos sujeitos, no seu ambiente de convivência familiar e comunitária. As visitas domiciliares " [...] têm como objetivo conhecer as condições (residência, bairro) em que vivem tais sujeitos e apreender aspectos do cotidiano das suas relações, aspectos esses que geralmente escapam as entrevistas de gabinete" (Mioto, 2001, p. 148).

Contudo, o/a assistente social do CREAS opta por fazer uso da visita domiciliar quando compreende a necessidade da atividade profissional requerendo competência e disponibilidade do/a profissional para realizá-la, inclusive podendo ser cumulativa a outros instrumentos.

Desse modo, o/a assistente social, ao se deparar com a realidade social, deve refletir criticamente, tomando por base a razão ética, as legislações que atendem os sujeitos protagonistas das demandas, conhecê-la em sua totalidade e optar pelos instrumentos viáveis e capazes de atender à situação, possibilitando uma resposta plausível na perspectiva da viabilização de direitos da população usuária dos serviços, no caso em questão do SUAS, através dos serviços ofertados pela proteção social especial.

Por meio do trabalho o homem se afirma como ser criador, não só como indivíduo pensante, mas como indivíduo que age consciente e racionalmente. Sendo o trabalho uma atividade prático-concreta e não só espiritual, opera mudanças tanto na matéria ou no objeto a ser transformado, quanto no sujeito, na subjetividade dos indivíduos, pois permite descobrir novas capacidades e qualidades humanas (Iamamoto, 2004, p. 60).

Iamamoto e Carvalho (1982) tecem as reflexões sobre as transformações no mundo do trabalho, refletindo novas configurações, cenários e, consequentemente, expandindo o processo de desigualdade através das diversas expressões da questão social, passando a demandar da categoria conhecimento técnico com o desígnio de sustentar a prática profissional na proposição de intervenções pertinentes aos atendimentos ofertados aos usuários.

Para dar concretude aos atendimentos por meio das intervenções, o/a assistente social utiliza informações, habilidades e instrumentos técnicos que são elementos norteadores na obtenção de conhecimento de uma dada realidade, no entanto, a discussão de "como fazer" é complexa no cotidiano de trabalho da profissão. Segundo Guerra (2007, p. 30): "Para além das definições operacionais (o que faz, como faz), necessitamoscompreender "para que" (para quem, onde e quando fazer) e analisar quaisas consequências que o nível "mediato" as nossas ações profissionais produzem".

Contemporaneamente, as demandas do/a assistente social vêm crescendo aceleradamente, principalmente em decorrência do atual cenário de pandemia da Covid-19 que o país se encontra desde o início do ano de 2020, que apresenta reflexos de uma conjuntura de governo fortalecido pelos ideais neoliberais, ocasionando expansão da desigualdade social em suas diferentes nuances, impactando, sobretudo, a luta pela sobrevivência de inúmeras famílias e indivíduos.

Não obstante, faz-se necessário reforçar o debate acerca do papel do/a assistente social frente a seus espaços de trabalho a fim de se fazer compreender quais são suas competências e habilidades, o que lhes dá base de fundamentação teórica e os 
legitimam enquanto categoria. Mas, para consolidar o que se compreende como "prática profissional" é necessário contar com alguns elementos, como os meios de trabalho, a matéria-prima e os objetos da ação. Iamamoto reflete sobre:

A leitura hoje predominante da "prática profissional" é de que ela não deve ser considerada "isoladamente", "em si mesma", mas em seus "condicionantes" sejam eles "internos" - os que dependem do desempenhoprofissional - ou "externos" - determinados pelas circunstâncias sociaisnas quais se realiza a prática do assistente social. Os primeiros são geralmente referidos a competências do assistente social como, por exemplo, acionar estratégias e técnicas; a capacidade de leitura da realidade conjuntural, a habilidade no trato das relações humanas, a convivência numa equipe interprofissional etc. Os segundos abrangem um conjunto de fatores que não dependem exclusivamente do sujeito profissional, desde as relações de poder institucional, os recursos colocados à disposição para o trabalho pela instituição ou empresa que contrata o assistente social; as políticas sociais específicas, os objetivos e demandas da instituição empregadora, a realidade social da população usuária dos serviços prestados etc. (Iamamoto, 2004, p. 94).

Nesse sentido, pensar sobre instrumentalidade é sinônimo de conhecimento, planejamento e articulação para a realização de uma ação, levando em consideração a dimensão técnica operativa que consiste em ter clareza e domínio mediante as intervenções a serem feitas, primando pela finalidade do ato como resultado positivo diante da demanda apresentada.

A fusão das competências se dá baseada na compreensão da formação profissional articulada à clareza das competências e habilidades que circundam o fazer profissional por meio de sua prática e função social.

\section{A Instrumentalidade do Serviço Social na Proteção Social Especial: a realidade da prática profissional no CREAS de Novo Oriente/CE}

O CREAS de Novo Oriente/CE se encontra situado na Rua Coelho da Silva, n. ${ }^{\circ}$ 90, Centro, com horário de funcionamento reduzido devido ao contexto pandêmico, funcionando de $07 \mathrm{~h}$ às $12 \mathrm{~h}$, de segunda a sexta-feira, com atendimento remoto, presencial e in loco.

Conta com estrutura física adequada, sendo composto por 1 sala de atendimento individual, garantindo o sigilo e privacidade; 1 sala de atendimento coletivo; 3 banheiros com acessibilidade parcial; veículo compartilhado 3 vezes na semana, 3 computadores e telefone móvel institucional. A equipe técnica se encontra completa e atende às especificações, conforme as recomendações da NOB/RH - SUAS e da Resolução CNAS n. ${ }^{\circ}$ 17/2011.

As demandas que chegam ao CREAS de Novo Oriente podem ser de forma anônima ou espontânea, ficando a critério da equipe técnica a metodologia viável para realizar o atendimento com o objetivo de intervir na realidade do usuário para além da apreensão inicial da demanda, por isso se reforça a importância da instrumentalidade enquanto processo de trabalho, no sentido de compreender a finalidade das ações adotadas.

Dentre os instrumentos e técnicas utilizadas pela assistente social, a visita domiciliar é pioneira em atendimento, pois se entende que o atendimento institucional, por vezes, não é suficiente para apreensão da realidade, e, em muitos casos, uma das limitações dos usuários é se deslocar para o equipamento, seja pela dificuldade de acesso ou mesmo pelo teor da demanda.

A definição dada por Samaro (2014) para Visita Domiciliar consiste em:

[...] é uma técnica social, de natureza qualitativa, por meio da qual o profissional se debruça sobre a realidade social com a intenção de conhecê-la, descrevê-la, compreendê-la ou explicá-la. O seu diferencial em relação a outras técnicas é que tem por lócus o meio social, especialmente o lugar social mais privativo e que diz respeito ao território social do sujeito: a sua casa ou local de domicílio. Samaro (Samaro, 2014, p. 19).

Levando em consideração o cenário de pandemia que o país se encontra, é necessário ressaltar que os números de violência apresentam crescimento, uma vez que as famílias estão mais restritas às suas casas, as escolas fechadas, dentre outros aspectos que deixam as famílias mais vulneráveis. Diante desse cenário, o número de denúncias através do aplicativo de WhatsApp é crescente no CREAS de Novo Oriente. Ao realizar o atendimento remoto, são dadas as devidas orientações acerca 
da demanda, e no caso de extrema urgência é realizado o agendamento para realização de visita domiciliar, quando a profissional precisa ir in loco, conta com todos os equipamentos de proteção individual para realizar o atendimento.

Com a chegada da vacina e o plano de retomada das atividades, atualmente o CREAS apresenta expansão na realização de visitas domiciliares, buscando atender as demandas em tempo hábil, obedecendo ao planejamento das atividades do equipamento, sendo as visitas domiciliares realizadas às quartas e quintas-feiras, devido ao carro ser compartilhado com o CRAS.

Dentre os instrumentos e técnicas utilizados pela assistente social do CREAS de Novo Oriente, a visita domiciliar assume o maior percentual de atuação frente às demandas apresentadas ao equipamento. Ao optar pelo uso da visita domiciliar como metodologia de trabalho, é importante salientar o quanto o desenvolvimento da atividade é algo íntimo, pois não se pode perder de vista a importância da ética, inclusive, se possível, comunicar as famílias sobre a realização da visita para deixá-las cientes. Na oportunidade, é preciso compreender que poderá se deparar com diversos contextos de famílias, ambientes de moradia, dentre outras particularidades, sendo necessário deixar claro o objetivo da perspectiva da viabilização de direitos, rompendo com os paradigmas de práticas higienistas e fiscalizatórias.

É preciso identificar a realidade exatamente como ela se apresenta, levando em conta as condições sociais e culturais daqueles sujeitos, sem interpretações que venham ao encontro de seus conceitos morais e culturais. Esse cuidado é de suma importância, pois o conhecimento acerca da vida social daqueles sujeitos deve compreender a sua história de vida, com suas particularidades, sem preconceitos e discriminação.

Não se pode esquecer que o local onde se desenvolve a visita domiciliar é privativo dos sujeitos, onde a realidade social se apresenta de modo diferenciado da que vive o profissional, e "[...] capturar a realidade dentro de seu quadro social e cultural específico exige do profissional a visão de seus elementos difíceis, intrigantes e conflitantes, por mais estranhos que eles possam parecer a nossa razão" (Amaro, 2003, p. 31).

Contudo, a visita domiciliar sempre foi um dos principais instrumentos de controle das classes populares que as instituições utilizaram. Uma vez que o/a usuário/a está sendo atendido/a na instituição, ele/a está acionando um espaço público: quando a instituição se propõe a ir até a casa do/a usuário/a, ela está adentrando no terreno do privado. A residência é o espaço privado da família que lá vive. Ter essa dimensão é fundamental para que a assistente social rompa com uma postura autoritária, controladora e fiscalizadora ${ }^{5}$.

Portanto, a assistente social, ao chegar ao endereço referenciado, apresenta-se enquanto técnica do CREAS, informando o motivo da visita domiciliar. Outro fator relevante é respeitar o espaço do interlocutor, no caso da família, como também subsidiar a realização do atendimento in loco, garantindo o sigilo das informações, evitando realizar a construção do diálogo na presença de estranhos, por exemplo, a não ser por pessoas autorizadas pelos próprios sujeitos.

\section{Conclusão}

Através da construção deste relato de experiência, percebe-se que o "fazer" profissional do/a assistente social, bem como o recurso da instrumentalidade em sua ampla conceituação, associada ao método técnico operativo da profissão, visa proporcionar uma transformação na vida dos usuários através da metodologia utilizada para nortear a condução das demandas. Neste caso em específico, o estudo consiste na reflexão acerca da visita domiciliar enquanto instrumento metodológico de intervenção, baseando-se nos princípios éticos fundamentais do código de ética, como também nas orientações pertinentes à lei de regulamentação da profissão.

\footnotetext{
${ }^{5}$ Uma interessante reflexão sobre o papel histórico que a visita domiciliar cumpriu na história do Serviço Social, bem como o seu caráter controlador e autoritário pode ser encontrado em Verdès-Leroux (1986), bem como em Martinelli (2005).
} 
Nesse sentido, os instrumentos que compõem o processo da instrumentalidade são responsáveis por conduzir a materialização do trabalho profissional na busca de atender às necessidades da população usuária, nesse caso voltadas para a atuação do/a assistente social na proteção social especial. Não restrito a isso, a instrumentalidade se refere, também, às competências e habilidades adquiridas ao longo da prática cotidiana do profissional, envolvendo todo o arcabouço teórico absorvido ao longo do exercício da profissão.

Portanto, percebe-se a importância de vislumbrar o significado sócio-histórico da instrumentalidade como condição do exercício profissional do/a assistente social, resgatar a natureza e a forma das políticas sociais que, como possibilidades de intervenção profissional, atribuem determinadas configurações, conteúdos e dinâmicas ao exercício profissional (Guerra, 2007).

\section{Referências}

Brasil. (1993). Lei $n^{\circ}$ 8.742, de 7 de dezembro de 1993. Dispõe sobre a organização da Assistência Social e dá outras providências. Brasília: Presidência da República. http://www.planalto.gov.br/ccivil_03/leis/18742.htm

Brasil. (2001). Constituição da República Federativa do Brasil de 1988. (27ª ed.): Saraiva.

Amaro, S. (2003). Visita domiciliar: guia para uma abordagem complexa. Porto Alegre: AGE.

Carneiro, D. Z. M. (2010). Custeio da seguridade social: aspectos constitucionais e contribuições específicas. São Paulo: Atlas.

Ceará. (2020). Decreto n. 33.510, de 16 de março de 2020. Governo do Estado do Ceará. https://www.ceara.gov.br/wp-content/uploads/2020/04/DECRETON\%C2\%BA33.510-de-16-de-mar\%C3\%A7o-de-2020.pdf

Ceará. (2021). Decreto n. 34.254, de 18 de setembro de 2021. Governo do Estado do Ceará. Recuperado de https://www.ceara.gov.br/wpcontent/uploads/2021/09/DECRETO-No34.254-de-18-de-setembro-de-2021.pdf

Couto, B. R., et al. (2010). O Sistema Único de Assistência Social: uma realidade em movimento. São Paulo: Cortez.

Freire, P. (2003). Pedagogia da autonomia: saberes necessários à prática educativa. São Paulo: Paz e Terra.

Goin, M., \& Bavaresco, L. (2009). Instrumentalidade Profissional: as mediações da prática profissional. I Jornada Interdisciplinar de Pesquisa das Faculdades Integradas Machado de Assis, 2009, Santa Rosa/RS. I Jornada Interdisciplinar de Pesquisa.

Gonçalves, E. P. (2001). Iniciação à pesquisa científica. Campinas: Editora Alínea.

Guerra, Y. (2007). A Instrumentalidade do Serviço Social. (5ª ed.) São Paulo: Cortez.

Guerra, Y. (2008). A instrumentalidade no Trabalho do Assistente social. Conselho Regional de Serviço Social de Minas Gerais - 6ª Região. (Org.). Simpósio Mineiro de Assistentes Sociais. Belo Horizonte: CRESS 6 ${ }^{a}$ Região, v. 1, p. 50-51.

Iamamoto, M. V. (2004). O serviço social na contemporaneidade: trabalho e formação profissional. (7a . ed.): Cortez.

Iamamoto, M. V., \& Carvalho, R. (1982). Relações sociais e serviço social no Brasil: esboço de uma interpretação histórico metodológica. São Paulo: Cortez.

Marconi, M. A., \& Lakatos, E. M. (1992). Metodologia do trabalho científico. São Paulo: Editora Atlas.

Martinelli, M. L. (2005). Pensar a identidade: eis a tarefa. Um ensaio sobre a identidade profissional do Serviço Social. Karsch, U. (org.) Estudos do Serviço Social: Brasil e Portugal. v. 2. São Paulo: EDUC.

Mioto, R. C. T. (2001). Perícia social: proposta de um percurso operativo. Serviço Social e Sociedade, n. 67, p. 145-158.

Netto, J. P. (2005). O Movimento de Reconceituação: 40 anos depois. Revista Serviço Social e Sociedade, n. 84, ano XXVI. São Paulo: Cortez.

Samaro, S. (2014). Visita domiciliar: teoria e prática. (1ª ed.): Papel Social.

Verdès-Leroux, J. (1986). Trabalhador social: prática, habitus, ethos, formas de intervenção. São Paulo: Cortez. 